\title{
ORGANISING INSIGHTS INTO SIMULATION PRACTICE
}

\author{
Michael Pidd \\ The Management School \\ University of Lancaster \\ Lancaster, LA1 4YX, U.K.
}

\author{
Stewart Robinson \\ Warwick Business School \\ University of Warwick \\ Coventry, CV4 7AL, U.K.
}

\begin{abstract}
Developments in simulation methodology have been so successful that simulation methods are used in many different domains, and many of these applications are based on discrete event simulation. Though many regard simulation modelling as an art, it ought to be possible to provide guidelines for the development of successful simulation applications. It is clear, though, that such guidelines must reflect the diversity of applications. We explore that diversity and comment on its effects.
\end{abstract}

\section{INTRODUCTION}

Even a brief examination of the proceedings of simulation conferences, such as the Winter Simulation Conference, shows the diversity of systems being simulated and also the range of reasons for developing and using a simulation approach.

Simulation models have been developed in domains such as:

- Manufacturing - plant layout and sizing, plant optimization, process design,

- Health care - clinic planning, blood transfusion services, AIDS transmission, renal dialysis services,

- Business process improvement,

- Air travel - airport operations, air traffic control,

- Road transport - traffic simulations, on-line traffic control,

- Emergency planning - evacuation modeling,

- Military - acquisition, analysis, training and mission rehearsal.

Some of these simulations were conducted to answer specific questions of interest to organisations in the public and private sectors. Others were more general and aimed to improve understanding of the operations of the system of interest. In some cases, the model was only intended for one-time use in a particular project but, in others, it was intended for use at intervals over an extended period of time; possibly for decades. Sometimes, model fidelity and accuracy of representation are crucial, but in other work, a model that gives broad indications of likely behaviour is good enough.

Hence, it seems sensible that attempts to improve the process of model development and use should recognise these distinctions. That is, advice and recommendations about model development, documentation, validation, use and re-use should, at the very least, be contingent. Indeed, it suggests that terms such as 'the simulation life cycle' may be misleading, since there may be many different types of life cycle depending on the nature of the simulation study (Sargent et al. 2006). In some cases there may not be a life cycle at all, for instance, for simulation projects in which quick and dirty models are developed that are never intended for re-use or detailed work.

That is, people 'do' modelling and simulation differently, taking different approaches to model development and to using the model. Can these different modes of practice be identified and classified? If so, this should aid discourse between different practice modes and aid selection of the right practice mode for a specific problem situation.

\section{SOME FRAGMENTS OF INSIGHT}

Robinson (2002) approaches this issue by suggesting 3 stereotypes of simulation practice that can be arranged on the spectrum of Figure 1. Note that these stereotypes are not dependent on the application domain, since it is perfectly possible for any of the 3 to be applied in the same domain (e.g. the defence sector).

\subsection{Three Stereotypes of Simulation Practice}

The left hand end of Figure 1 shows simulation as software engineering, which refers to simulation models developed using formal development approaches. Typically, such models are developed by relatively large teams in which model specification is separated from model cod- 


\section{Pidd and Robinson}

ing and documentation standards are rigidly enforced. Often, such models are intended for re-use either in full, or in part. Such approaches are relatively common in the defence sector and in other government contracts. Essentially, the model is treated as a software artefact that exists as an entity that is separate from those who specified it, those who developed it and those who may use it. Underpinning such simulations there is likely to be considerable analytical work in data analysis and theories, for example about physical object interaction.

$\begin{array}{lll}\text { Software Engineering } & \begin{array}{c}\text { Modelling as } \\ \text { Process of } \\ \text { Organisational Change }\end{array} \\ \text { Large models } & \text { Medium models } & \text { Quick-and-dirty models } \\ \text { Reusable } & \text { Throw-away } & \text { Throw-away } \\ \text { Prog. language } & \text { VIMS } & \text { VIMS } \\ \text { Mevelopment over years } & \text { Development over weeks } & \text { Development over days } \\ \text { Software development } & \text { One modeller } & \text { One modeller } \\ & \text { Problem intervention } & \text { Facilitating debate }\end{array}$

Figure 1: Robinson's simulation modes of practice.

The opposite end of Figure 1 shows simulation to support facilitation. Such models are usually developed using visual interactive modelling systems (VIMS) and are certainly not intended for re-use, since they are typically very approximate, which causes some to label this as 'quick \& dirty' simulation. The models, and often there is a sequence of such models, are constructed to improve understanding more than to answer specific questions. They may be built with the client at hand. In extreme cases, such models may not embody reality; instead they are convenient fictions that support debate.

In the middle of the spectrum of Figure 1 is simulation for organisational change. This refers to simulations developed to address problems related to real-world issues - often in management science or industrial engineering - and in which the models may be used over a period of several weeks or months. Often such models are successively refined in an iterative process over that period and may be based on substantial data analysis. In some sense, such models are intended as representations of reality (albeit on a simplified basis). As on the right hand end of Figure 1, such models are usually built using VIMS, but will have required significant effort in code development beyond simple point and click model development.

\subsection{Four Different Modes of Model Use}

Taking a slightly different tack, but also employing a spectrum of use, Pidd (2003, chapter 1) suggests four different modes of model use as shown in Figure 2. Note that Pidd (2003) is concerned with modelling approaches that include, but are not limited to, computer simulations. That is, it is concerned with the broader set of approaches that are often included within a range of approaches to systems modelling. It is obvious;y possible that one or more of the four points on the spectrum do not apply to simulation. Perhaps the most likely to be inapplicable to simulation, is modelling to support the automation of decisions.

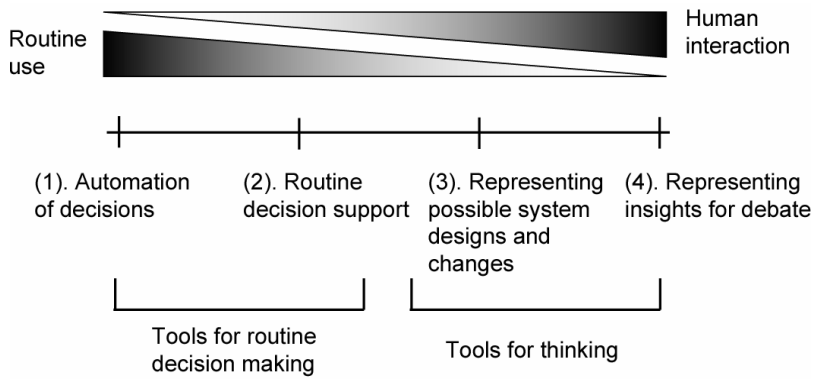

Figure 2: Pidd's spectrum of model use.

At the extreme left hand end of Figure 2 are models that are intended to support automated decision making. That is, they capture and systematise human insight in such as way as to replace human decision making. Examples might be the models that underpin fly by wire and autopilots on aircraft or engine management and braking systems on cars. As mentioned above, this may be the least likely to be relevant to a discussion on simulation, especially if simulations contain stochastic elements. Closer to the centre of Figure 2 are models intended for routine decision support. Examples include the revenue management systems that are used to support on-line bookings of aircraft seats and scoring systems that allow rapid decisions on consumer credit or insurance. These also replace human decision makers, but humans will regularly adjust the model parameters as the world changes. For example, an airline may modify its revenue management system after a strike by its staff and the consequent loss of revenue. Pidd (2003) refers to the left side of Figure 2 as models that automate routine decision making.

Moving to the centre right of Figure 2 are models intended for use in exploring options for system change, design or re-design. These models often require substantial technical effort to build and need careful validation as they may form the basis for decisions requiring substantial investment. Examples might include a simulation of an airport passenger terminal before it is built, so as to ensure that passenger delays and bag losses are kept as low as possible. Finally, at the right hand end of Figure 2 are models that are intended to represent different insights; that is, to explicate mental models so that they can be explored and examined by other people. In mathematical or computing terms, these models may be very simple and their power rests in the ways in which they are used. Pidd (2003) refers to the right side of Figure 2 as models that are tools for thinking. 


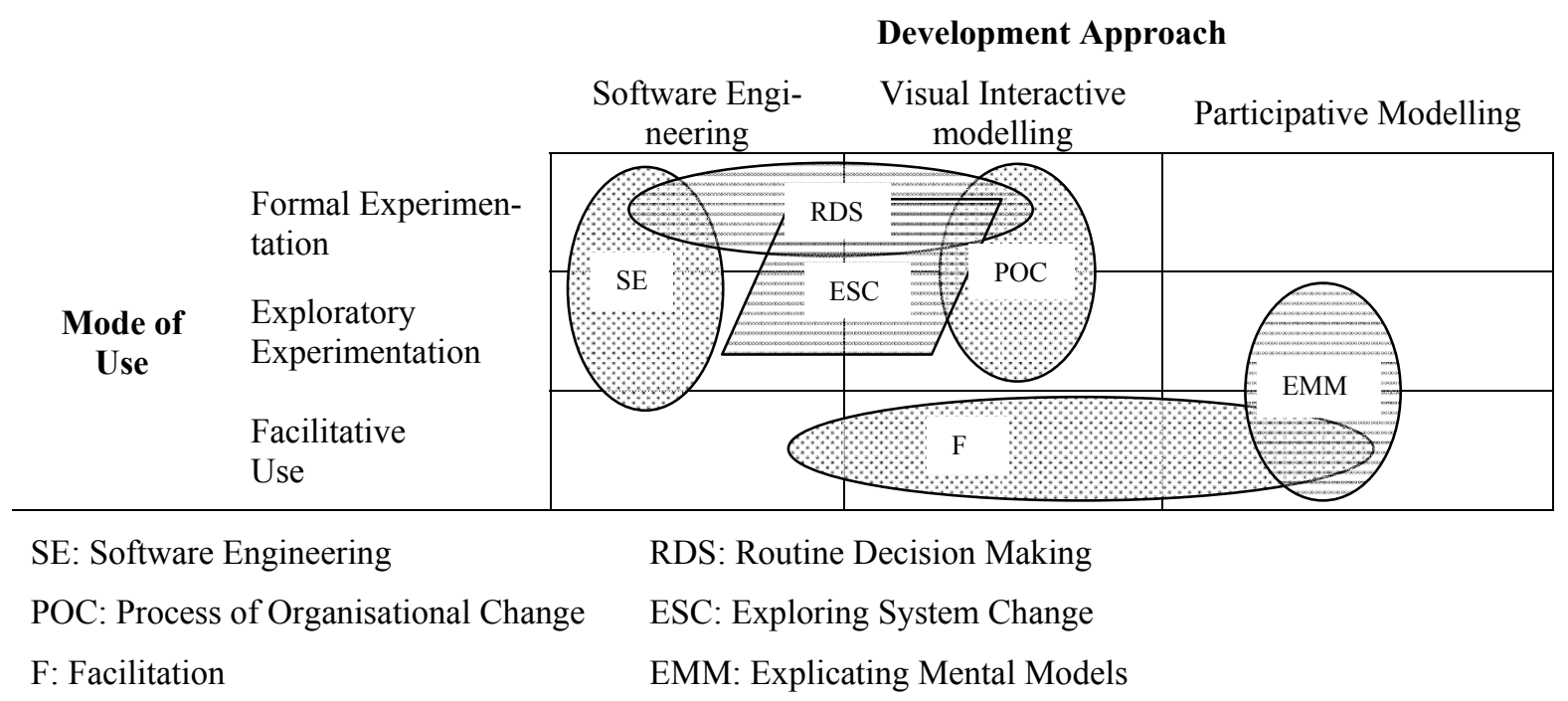

Figure 3: Two dimensional model of simulation practice modes (with mapping of Robinson's and Pidd's practice modes).

\section{SEEKING CONCEPTUAL CLARITY}

In presenting these two spectra it is apparent that there is some confusion in the criteria being used to categorise the different approaches. Though both claim to focus on model use and are indeed expressed in those terms, there is more to their descriptions than that. To tease this out, it may be helpful to consider a 2 dimensional model instead, using Development Approach and Mode of Use; where development approach is associated with modelling and mode of use with simulation. Without such a distinction, there could be a tendency to assume that it is always OK for models intended as tools for thinking or as convenient fictions to be developed in a slapdash way. Such a twodimensional representation also highlights aspects of distinct support tools that might be needed by analysts operating in the various domains. Figure 3 shows the basic idea.

In Figure 3, the two dimensions are split into three levels each. Under Model Development is:

- Software Engineering: refers to the use of formal methods for the development of the model. This might range from more traditional software development approaches (e.g. the waterfall life cycle) through to current ideas of Xtreme programming and agile programming. Such an approach is common in military modelling and simulation.

- Visual Interactive Modelling: development of the model through less formal means (e.g. with no technical specification), using a VIMS. This is typical of the type of modelling that is carried out in business organizations.
- Participative Modelling: development of the model with the participation of the client. The model developer and the client would develop the model together, possibly in a workshop environment. This, by nature, requires rapid model development in a flexible software tool. This sort of approach is more common in the field of system dynamics (e.g. Vennix 1996), but certainly could become part of mainstream discreteevent simulation practice if appropriate tools were available.

Meanwhile, under Model Use is:

- Formal Experimentation: adoption of formal experimentation procedures such as experimental design methods, ranking and selection approaches, hypothesis testing and simulation optimisation. These approaches are described in text books such as Law (2007) and Banks et al. (2005), as well as being discussed in the Analysis Methodology track of the annual Winter Simulation Conference.

- Exploratory Experimentation: experiments performed to provide statistically sound results (e.g. confidence intervals), but with no formal search procedure to guide the selection of experiments. Robinson (2004) describes a number of informal experimental approaches.

- Facilitative Use: intuitive use of the model, with learning gained from debate around watching the visual display and indications gained from model results. There is no emphasis on instrumental learning from statistically sound results. Instead 
the focus is on conceptual learning. For an example of this see Robinson (2001).

The intention is not to create artificial boundaries between these 2 sets of 3 levels by suggesting that they are discrete. Indeed, these levels should be seen as sections along a continuum moving from very formal Software Engineering approaches to very informal Participative Modelling, and from Formal Experimentation to Facilitative Use.

Included in Figure 3 is a mapping of Robinson and Pidd's original modes of practice. These are provided as a guide to show how these modes relate to the two dimensions. So, for instance, under Robinson's 'Software Engineering' mode, models were developed using the Software Engineering Development Approach, but could be used under any of the 3 Modes of Use - although Facilitative Use is probably less likely.

Having mapped these original modes, it is notable that the bottom left and top right blocks of Figure 3 are almost empty. This is because these are extreme situations are likely to be very rare. It seems clear that taking a formal Software Engineering approach to model development serves little purpose when the model is intended as an almost ad-hoc tool to support debate (Facilitative Use), although we might argue that simulation gaming is an example of this. In such situations, the need is generally for rapid model creation and the ability to run a model on rather sparse data. The idea is that the model allows participants to develop insights into a situation and to separate those insights from the individual participants so that they are no longer someone's opinion. Instead, the observed behaviour rests in the models. Similarly, it is unlikely that a model developed in a participative fashion would be subject to Formal Experimentation. The lack of real world correspondence and low accuracy of the data contained in such models would generally make Formal Experimentation pointless.

\section{CONCLUSION}

The model of simulation practice modes in Figure 3 aims to provide a framework for understanding and debating simulation practice. Without an underlying understanding of the different approaches adopted to simulation model development and use, it is difficult to form a coherent discussion between different modellers, and the discourse can easily break down.

At present this model is purely a proposition based on the authors' experience in modelling and simulation. The model requires development and refinement through discussion with other simulation modellers and through testing it in discourse about simulation practice. As it stands, however, we hope that it provides a useful base from which to build a debate about the practice of simulation model development and use.

\section{REFERENCES}

Banks, J., J. S. Carson, B. L. Nelson, and D. M. Nicol. 2005. Discrete-Event System Simulation, $4^{\text {th }}$ ed. Upper Saddle River, New Jersey: Prentice-Hall, Inc.

Law, A. M. 2007. Simulation Modeling and Analysis, $4^{\text {th }}$ ed. New York: McGraw-Hill.

Pidd, M. 2003. Systems Modelling: Theory and Practice. Chichester, United Kingdom: John Wiley \& Sons.

Robinson, S. 2001. Soft with a hard centre: discrete-event simulation in facilitation. Journal of the Operational Research Society. 52(8): 905-915.

Robinson, S. 2002. Modes of simulation practice: approaches to business and military simulation. Simulation Practice and Theory. 10: 513-523.

Robinson, S. 2004. Simulation: The Practice of Model Development and Use. Chichester, United Kingdom: Wiley.

Sargent, R. G., R. E. Nance, C. M. Overstreet, S. Robinson, and J. Talbot. 2006. The simulation project lifecycle: models and realities. In Proceeding of the 2006 Winter Simulation Conference, ed. L. F. Perrone, F. P. Wieland, J. Liu, B. G. Lawson, D. M. Nicol, and R. M. Fujimoto, 863-871. Piscataway, New Jersey: Institute of Electrical and Electronics Engineers, Inc.

Vennix, J. A. M. 1996. Group Model Building: Facilitating Team Learning using System Dynamics. Chichester, United Kingdom: Wiley.

\section{AUTHOR BIOGRAPHIES}

MICHAEL PIDD is Professor of Management Science in the Department of Management Science at Lancaster University Management School. He is known for books that discuss modelling (Tools for thinking: modelling in management science; Systems modelling: theory and practice) and on simulation (Computer simulation in management science) all published by John Wiley. His curiosity causes his research interests to wander through time and he is currently interested in simulation modelling in health system improvement, the way that management scientists develop models and the improvement of simulation methods. He can be contacted by e-mail via $<\mathrm{m}$.piddelancaster.ac.uk $>$. His Web address is: $<$ www.lancs.ac.uk/staff/smamp/>.

STEWART ROBINSON is Professor of Operational Research and the Associate Dean for Specialist Masters Programmes at Warwick Business School. He holds a BSc and $\mathrm{PhD}$ in Management Science from Lancaster University. Previously employed in simulation consultancy, he supported the use of simulation in companies throughout 
Europe and the rest of the world. He is author/co-author of three books on simulation. His research focuses on the practice of simulation model development and use. Key areas of interest are conceptual modelling, model validation, output analysis and modelling human factors in simulation models. His email address is <stewart.robinsonewarwick.ac.uk>, and his Web address is <www.btinternet.com/ stewart.robinson1 /sr.htm>. 